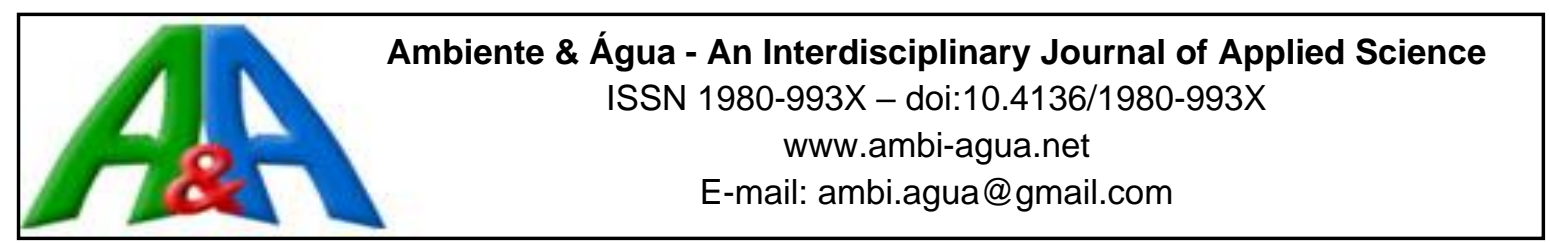

\title{
O desafio da interdisciplinaridade nos Programas de Pós-graduação em Ciências Ambientais
}

\author{
doi:10.4136/ambi-agua.1915
}

Received: 28 Aug. 2016; Accepted: 17 Nov. 2016

\author{
Marcelo dos Santos Targa ${ }^{*}$; Ana Aparecida da Silva Almeida ${ }^{1}$; \\ Maria Dolores Alves Cocco ${ }^{1}$ \\ ${ }^{1}$ Universidade de Taubaté (UNITAU), Taubaté, SP, Brasil \\ Programa de Pós-Graduação em Ciências Ambientais \\ *Autor correspondente: e-mail: mtarga@unitau.br, \\ anasilva@unitau.br,maria.cocco@unitau.com.br
}

\section{RESUMO}

Nesses 18 anos de experiência no ensino de pós-graduação na Área Ambiental da Universidade de Taubaté, os Programas de Pós-graduação em Ciências Ambientais (PPGCA), mestrado profissional e mestrado acadêmico vêm se consolidando no trato de questões ambientais em condições geográficas distintas, associadas ao desenvolvimento da região metropolitana do Vale do Paraíba, São Paulo, bem como a questões ambientais na região amazônica. A presente edição da Ambi-Água apresenta 15 artigos originais oriundos de dissertações defendidas nos últimos três anos, os quais reforçam o desafio no tratamento das questões ambientais em um contexto interdisciplinar. É notório o compromisso do PPGCA na construção de conhecimento na área ambiental que deve nortear o desenvolvimento dessa importante região metropolitana do estado de São Paulo.

Palavras-chave: ciências ambientais, formação ambiental, interdisciplinaridade, meio ambiente.

\section{The challenge of interdisciplinarity in Graduate Programs in the Environmental Sciences}

\begin{abstract}
During 18 years of experience in graduate education in the environmental area, the graduate programs in environmental sciences of the University of Taubate have been consolidating the treatment of environmental issues in different geographic conditions, associated with the development of the metropolitan region of Vale do Paraíba, São Paulo, as well as environmental issues in the Amazon region. This edition of Ambi-Água presents 15 original articles from dissertations presented in the last three years, which reinforce the challenge in the treatment of environmental issues in an interdisciplinary context. The commitment of the PPGCA in the construction of knowledge in the environmental area that must guide the development of this important metropolitan region of the state of São Paulo is well known.
\end{abstract}

Keywords: environment, environmental graduation, interdisciplinarity, master's degree. 


\section{INTRODUÇÃO}

A Universidade de Taubaté - UNITAU é uma universidade pública municipal do estado de São Paulo, que oferece dois Programas de Pós-graduação em Ciências Ambientais (PPGCA), um mestrado profissional e o mestrado acadêmico, os quais são resultantes da evolução de um Programa de Pós-graduação em Engenharia Ambiental - mestrado profissional e doutorado, implantado em 1998 na vigência da Resolução CFE no. 05/1983. Após dois anos de funcionamento do mestrado e doutorado como Engenharia Ambiental, em função de aspectos multidisciplinares de formação dos ingressantes, constata-se que não havia relação direta com os cursos das engenharias, como inicialmente proposto, de modo que foram redimensionadas as disciplinas, o quadro docente, bem como a denominação passa a ser Programa de Pós-graduação em Ciências Ambientais - PPGCA, mestrado profissional (Targa e Almeida, 2013).

Em 2009, seguindo as orientações da Comissão de Visita e Acompanhamento a Programas de Pós-graduação da CAPES, foi proposto um segundo modelo de mestrado em Ciências Ambientais, nível acadêmico, com uma única linha de pesquisa intitulada "Composição e Processos Estruturantes de Bacias Hidrográficas - CPEBH", baseado no princípio da Lei 9433/97, Política Nacional de Recursos Hídricos, que tem a bacia hidrográfica como unidade territorial e sistêmica de análise.

O mestrado profissional em 18 anos de existência titulou 354 mestres, tendo marcante vocação no desenvolvimento de dissertações com foco em problemas ambientais na região vale-paraibana paulista (85\%) e região amazônica (15\%). Por outro lado o mestrado acadêmico que iniciou suas atividades em 2011 titulou 27 mestres que defenderam suas dissertações avaliando questões ambientais da região metropolitana do vale do Paraíba e do litoral norte de São Paulo.

Assim, é claro o compromisso do PPGCA na construção de conhecimento interdisciplinar que norteia o desenvolvimento dessa importante região metropolitana do estado de São Paulo.

Com forte aptidão agrícola a região do vale do Paraíba no estado de São Paulo, como outras no Brasil, desde o século 16 tiveram suas lavouras dependentes da força do trabalho escravo.

Com a independência do Brasil em 1822 e o final da escravidão em 1888, iniciou-se uma política de produção e desenvolvimento, que alcançou grande impulso com a política do cultivo do café. Um exemplo dessa política de produção de café foi o Acordo de Taubaté (Convênio de Taubaté) de 1906 em que o governo federal comprava café excedente de produção com dinheiro vindo de empréstimos internacionais garantidos pelas exportações de café que por um tempo, ajudou a manter o valor de mercado do café. A produção de café começou nos estados do Rio de Janeiro, São Paulo e Minas Gerais, mais especificamente, no vale do rio Paraíba do sul. Esse foi o grande impulso do desenvolvimento do Brasil desde o início do século XIX até 1920, e a região vale-paraibana ganhou riqueza e poder político. Contudo, o reinvestimento na produção de café aumentou a oferta enquanto a demanda internacional não aumentou tão rapidamente, os cafeicultores influenciaram as políticas governamentais que, depois de um tempo, se tornaram insustentáveis e em 1929 o crash interrompeu empréstimos internacionais e diminuiu o valor de mercado do café. Essa influência governamental dos cafeicultores determinou o início do Estado-Providência na década de 1930 no Brasil a exemplo do que já teria ocorrido em outros países.

O Estado-Providência promoveu uma política de industrialização lenta que visava a substituição das importações e, dessa forma, iniciou-se com a indústria têxtil. Somente em 1956 foi implementado o Plano Nacional de Desenvolvimento que consistia em um plano de 31 metas visando desenvolver o Brasil 50 anos em 5, sendo essa última, a construção de 
Brasília e mudança da capital federal. Os planos eram ambiciosos e tiveram sucesso. A indústria de base, por exemplo, alcançou $100 \%$ das metas estabelecidas. Foi uma época de grande desenvolvimento, mas que utilizou muito capital do exterior. A expansão da base da indústria na área metropolitana de São Paulo produziu um efeito de transbordamento nas áreas vizinhas, localizadas a cerca de 1 hora de São Paulo, como as cidades Sorocaba, Campinas, Santos e São José dos Campos, com boa infraestrutura, mobilidade facilitada, migração interna acelerada, crescimento rápido da população, aumento da participação do PNB, mas que apresenta aumento de disparidades sociais e estabelecimento de desenvolvimento regional desigual.

O desenvolvimento tecnológico foi impulsionado pelas atividades do Centro Técnico Aeroespacial - CTA e do Instituto Tecnológico de Aeronáutica - ITA criados na década de 50, bem como a criação do Instituto Brasileiro de Pesquisas Espaciais (INPE) em 1961 e da Embraer em 1969.

Um aspecto importante e que muda as características sociais e econômicas de governança local, foi a criação da região metropolitana do vale do Paraíba e litoral norte por meio da lei complementar estadual 1.166, de 09 de janeiro de 2012 que visa à gestão compartilhada das funções públicas de interesse comum entre os municípios (EMPLASA, 2015).

Em meio ao vale do Paraíba, serra da Mantiqueira e o litoral norte, a região possui mais de $36 \%$ do seu território protegido por vinte e quatro Unidades de Conservação (UC) e a concentração do maior conjunto de patrimônio histórico do estado de São Paulo (Cocco et al., 2014).

As áreas protegidas e salvaguardadas desempenham importante papel para o equilíbrio de vários ecossistemas e o bem estar da sociedade, fundamentalmente desenvolvendo uma harmonia entre o meio construído e o natural. No entanto, a preservação e a conservação dessas áreas dependem de políticas públicas integradas.

Uma forte inserção social do PPGCA é o seu envolvimento com a política de preservação cultural na região do vale do Paraíba, que se faz por meio da integração com o desenvolvimento de atividades de extensão.As propostas de preservação desses bens culturais ambientais ocorre com os alunos dos cursos de graduação e pós-graduação constituindo-se num repertório acadêmico relevante à compreensão do processo histórico e às políticas de desenvolvimento do ambiente construído da região, contribuindo, ainda, na formação e na capacitação de mão-de-obra, responsabilidade que tem assumido como exemplo de um compromisso social com a região.

Do mesmo modo pesquisas a nível internacional sobre preservação de bens culturais têm provado que a conservação da herança deixada pelo homem é uma questão relevante para o equilíbrio entre as atividades humanas e o meio ambiente. Os projetos de extensão associados ao Programa de Ciências Ambientais, ainda não em números suficientes para atender a demandas da região, têm contribuído para ações voltadas à educação ambiental, promovendo a comunidade e gerando novas oportunidades de emprego.

Um dos problemas herdados, gerado ao longo dos anos, como reflexo da organização socioeconômica da região do vale do Paraíba é a conurbação das cidades ao longo da rodovia Presidente Dutra, importantes não só para o Estado, mas para o País, pois trata-se do terceiro PIB de São Paulo, ficando atrás apenas da capital e da região metropolitana de Campinas. A conurbação urbana que fisicamente é vista em situações de proximidade entre municípios como São José dos Campos e Jacareí, Taubaté e Tremembé, por exemplo, embora não seja realidade ainda para outros municípios, apresenta-se como uma tendência local.

O Programa de Ciências Ambientais nestes últimos dezoito anos tem contribuído com a construção de indicadores que viabilizam a análise do cenário histórico da região frente aos impactos da urbanização. A avaliação sob o ponto de vista de uso e da ocupação do solo 
(Batista et al., 2005), apoiado pela interdisciplinaridade do curso, proporciona ainda a análise dos aspectos antrópicos e ambientais de forma integrada.

No período de crescimento industrial vivido pela região do vale do Paraíba nas décadas de 1950, 1970 e 1980, os governos federal e do estado de São Paulo incentivaram à construção de estradas, ocasionando um aumento significativo da população às margens de rodovia, favorecendo a ação antrópica por meio de uma expansão urbana desordenada, levando os moradores ao abandono dos núcleos centrais tradicionais das cidades da região do vale do Paraíba. Essa ação incentivou o desmatamento e a impermeabilização do solo a favor de uma ocupação territorial com novo padrão de urbanização e uma alteração significativa na paisagem. E como desdobramento desse crescimento, várias cidades apresentam um déficit habitacional significativo, principalmente nos municípios com alta densidade, como a cidade de São José dos Campos, Taubaté, Jacareí, Pindamonhangaba, Guaratinguetá, Aparecida e no litoral norte a cidade de Caraguatatuba (IBGE, 2015).

A paisagem fisiográfica da região do vale do Paraíba mostra planície aluvial com altitude variando de 500-600 m acima do nível do mar, enquanto que a parte mais montanhosa corresponde à encosta ocidental da serra da Mantiqueira, à região nordeste da serra da Bocaina e, mais distante ainda, a serra do Mar (São Paulo, 1978).

A apropriação dos elementos naturais pela sociedade se dá por vários aspectos, destacando-se a extração de areia para uso na construção civil, que além de produzir consideráveis alterações ambientais na planície aluvial, gera conflito de uso do solo com a crescente urbanização da região e compromete a qualidade das águas superficiais e profundas (Reis et al., 2006). Outra situação crítica diz respeito ao uso de agrotóxicos nas atividades agropecuárias ainda praticadas nas áreas rurais persistentes na região.

O vale do Paraíba é uma das poucas regiões que participou de todos os ciclos econômicos sendo palco de todos os processos de industrialização brasileira, com destaque especial para os complexos aeroespacial e automobilístico. A despeito do elevado desenvolvimento econômico, a região não conseguiu equidade de distribuição de renda, pelo não efeito de transbordamento para as cidades periféricas (Vieira, 2009).

A dinâmica de ocupação e as atividades produtivas que permanecem ainda na região, caracterizada por ciclos de prosperidade e decadência marcam o contexto econômico e social, não só como centro econômico brasileiro, mas também, como região periférica e econômica e social de São Paulo e Rio de Janeiro, pois se por um lado São José dos Campos se apresenta como polo tecnológico aeroespacial reunindo centros de excelência em pesquisa e desenvolvimento, Guaratinguetá com indústrias e atividades na área química, Pindamonhangaba como pólo de reciclagem de alumínio e Taubaté como centro automobilístico e de mecânica pesada, de outro se têm as cidades que, embora prósperas no passado, atualmente vivem da exploração de sua ruralidade e potencial turístico, tais como Cunha, Bananal, Areias, São Luiz do Paraitinga, entre outras (Targa e Almeida, 2013).

É evidente que os problemas herdados desse desenvolvimento desigual da região faz aumentar as lacunas de renda, de alfabetização, de serviços públicos, etc., bem como a existência de economias de rápido crescimento, vizinhas às economias locais deprimidas.

A concentração urbana com mais de $90 \%$ da população regional originária da cinco cidades cortadas pela via Dutra e a proximidade com São Paulo associa-se à depreciação da vida rural e às diminuições das oportunidades de emprego, da capacidade de geração de renda e do uso de recursos naturais.

As ações governamentais estabelecidas como políticas públicas implementadas no vale do Paraíba são aquelas da área de meio ambiente, de recursos hídricos, de saúde, de resíduos, de saneamento, de agricultura etc., cujos programas são principalmente nas áreas de:

Agricultura - com objetivos de promover o desenvolvimento rural, por meio da ampliação das oportunidades do agronegócio, de pesquisa, da preservação dos recursos 
naturais e do bem-estar da comunidade, sendo a produção de arroz, gado de corte e leite, e produção florestal, mas ainda tem produção de café, milho, feijão, batata, hortaliças, bem como criação de pequenos animais, apicultura, pesqueiros.

Política de Energia - a região está voltada para a geração hidrelétrica e os estudos voltados para as questões hidrológicas e hidrosedimentométricas, conforme podem ser observados os trabalhos de Dias et al. (2009) e Vilaron e Fisch (2014).

Logística e transporte - a Confederação Nacional dos Transportes (CNT) em 2013 aponta que as rodovias da região estão entre as 10 melhores rodovias do Brasil, mas geram poluição em suas margens (Silva et al., 2013b).

Recursos Hídricos e Saneamento - uma das políticas que desde o início influenciou a criação e condução do PPGCA é o fato da existência na bacia do rio Paraíba do Sul de dois comitês: (1) o Comitê das Bacias Hidrográficas do Rio Paraíba do Sul - CBH-PS, responsável pela gestão dos recursos hídricos no trecho paulista da bacia e (2) o Comitê para Integração das Bacias do Rio Paraíba do Sul - CEIVAP de caráter Federal. Como a primeira bacia hidrográfica a implantar o seu comitê e a cobrança de água no estado de São Paulo, muitas interações entre mestrados profissional e acadêmico foram desenvolvidas como temas de dissertações. O PPGCA participa ativamente das câmaras técnicas e da plenária do Comitê das Bacias Hidrográficas do Rio Paraíba do Sul (CBH-PS), seja das reuniões, ou na propositura e desenvolvimento de projetos voltados para a melhoria dos recursos hídricos (Batista et al., 2005).

O conhecimento científico é a ponte necessária para estabelecer as amarrações entre as questões de sustentabilidade econômica, social e ambiental da região. Nesse contexto, o PPGCA conseguem produzir esse conhecimento de Ciências Ambientais aglutinando as questões sociais e econômicas.

Exemplos de pesquisas realizadas no PPGCA, profissional e acadêmico, enfocam de maneira integrada estudos de: hidrologia e hidrogeologia (Diniz et al., 2008), qualidade e reuso da água (Silva et al., 2013a), manejo do solo e da vegetação (de Paula et al., 2013), conservação da biodiversidade (Martins e Haddad, 2010) impactos da variabilidade climática (Vilaron e Fisch, 2014), geração e análise de cenários (Horikoshi e Fisch, 2007), impactos da urbanização e do uso da água (Targa e Batista, 2015), alterações da paisagem (Reis et al., 2006; Paiva Arguelo et al., 2010), preservação de bens culturais, análise dos impactos de políticas públicas (Cocco et al., 2014), destinação e processamento de resíduos urbanos e industriais (Assumpção et al. 2011; Silva et al., 2013a) e saúde ambiental (Nascimento et al., 2016) e da qualidade água (Salles et al., 2016).

Os trabalhos de dissertação desenvolvidos no PPGCA a despeito de estarem associados a estrutura curricular e formação dos docentes orientadores buscam a interdisciplinaridade, pois se entende que não se trata de eliminar as disciplinas curriculares, trata-se de torná-las comunicativas entre si, concebê-las como processos históricos e culturais, e sim torná-la necessária a atualização quando se refere às práticas do processo de formação dos novos mestres.

\section{CONSIDERAÇÕES FINAIS}

A complexidade dos problemas ambientais decorrentes do desenvolvimento econômico e social da região vale-paraibana, tais como a degradação ambiental, a produção de resíduos (doméstico e industrial), a poluição do ar, a poluição das águas superficiais e utilização de águas subterrâneas, a erosão do solo e movimento de massas, o esgotamento do habitat por meio do desmatamento e a plantação comercial de florestas, entre outros, exige a comunicação entre os estudos disciplinares, em um processo que integre as disciplinas a partir 
da compreensão das múltiplas causas dos problemas ambientais. Essa tarefa é um desafio que o PPGCA vem se dedicando ao direcionar os trabalhos dos estudantes dos mestrados profissional e acadêmico.

Embora a história de desenvolvimento da região vale-paraibana seja tão antiga quanto a história do Brasil, as estratégias devem centrar-se em compreender as questões ambientais de modo interdisciplinar a fim de que nossa sociedade regional possa para garantir $o$ desenvolvimento sustentável.

\section{REFERÊNCIAS}

ASSUMPÇÃO, J. G.; UENO, R.; FORTES NETO, P. Performance of wetland systems in the treatment of sewage generated at an educational institution, after a recession period. Revista Ambiente \& Água, v. 6, p. 165-178, 2011. http://dx.doi.org/10.4136/ambiagua.499

BATISTA, G. T.; CATELANI, C. S.; TARGA, M. S.; DIAS, N. W. Uso de geotecnologias na determinação de áreas degradadas, o caso da bacia do Rio Una, afluente do Rio Paraíba do Sul no cone leste paulista. In: CONGRESSO LATINO-AMERICANO DE DEGRADAÇÃO AMBIENTAL, 2005, Curitiba. Anais... [S.1.: s.n.], 2005. v. 1. p. 1-10.

COCCO, M. D. A.; VIERNO, F. M.; PERIM, M. A. Experiência pedagógica na construção de itinerários culturais regionais. IN: COLOQUIO IBERO-AMERICANO: PAISAGEM CULTURAL, PATRIMÔNIO E PROJETO, 3., 2014, Belo Horizonte. Trabalhos... Belo Horizonte: UFMG, 2014. Disponível em: https://goo.gl/XzMhzj. Acesso em: dez. 2016.

DE PAUlA, G. R.; BATISTA, G. T.; TARGA, M. dos S.; SOUZA, C. F.; DIAS, N. W.; PERES, J. G. Avaliação do comportamento da umidade do solo em áreas de eucalipto e de floresta nativa. Revista Ambiente \& Água, v. 8, p. 237-252, 2013. http://dx.doi.org/10.4136/ambi-agua.1419

DIAS, N. W.; DINIZ, H.; TARGA, M.; BATISTA, G. Geospatial technology applied to the identification of groundwater recharge areas in northeastern São Paulo, Brazil. Revista Ambiente \& Água, v. 4, p. 21-30, 2009. http://dx.doi.org/10.4136/ambi-agua.276

DINIZ, H.; DIAS, N. W. Hydrogeology and hydrodynamics of Tremembé aquifer, São Paulo, Brazil. Revista Ambiente \& Água, p. 108-137, 2008. http://dx.doi.org/10.4136/ambiagua. 120

EMPRESA PAULISTA DE PLANEJAMENTO (EMPLASA). Documento região metropolitana do Vale do Paraíba e Litoral Norte. 2015. Disponível em: http://www.emplasa.sp.gov.br/RMVPLN. Acesso em: dez. 2016.

HORIKOSHI, A. S.; FISCH, G. Balanço hídrico atual e simulações para cenários climáticos futuros no Município de Taubaté, SP, Brasil. Revista Ambiente - Água, v. 2, n. 2, p. 33-46, 2007. http://dx.doi.org/10.4136/ambi-agua.25

INSTITUTO BRASILEIRO DE GEOGRAFIA E ESTATÍSTICA - IBGE. Cidades. Disponível em: http://www.cidades.ibge.gov.br. Acesso em: 21 fev. 2015.

MARTINS, I. A.; HADDAD, C. F. B. A new species of Ischnocnema from highlands of the Atlantic Forest, Southeastern Brazil (Terrarana, Brachycephalidae). Zootaxa, v. 2617, p. 55-65, 2010. 
NASCIMENTO, L. F. C.; VIEIRA, L. C. P. F.; MANTOVANI, K. C. C.; MOREIRA, D. S. Air pollution and respiratory diseases: ecological time series. Sao Paulo Medical Journal, v. 134 , p. 315-321, 2016. http://dx.doi.org/10.1590/15163180.2015.0237250216

PAIVA ARGUELO, F. V. ; BATISTA, G. T.; PONZONI, F. J.; DIAS, N. W. Spatial distribution of Eucalyptus plantations in the São Paulo State portion of Paraíba do Sul river basin, Brazil. Revista Ambiente \& Água, v. 5, p. 133-146, 2010. http://dx.doi.org/ambi-agua.437

REIS, B. J.; BATISTA, G. T.; TARGA, M. S.; CATELANI, C. S. Influência das cavas de extração de areia no balanço hídrico do Vale do Paraíba do Sul. Revista da Escola de Minas, v. 4, p. 391-396, 2006. http://dx.doi.org/10.1590/S0370-44672006000400007

SALlES, F. J.; DE TOLEDO, M. C. B.; CÉSAR, A. C. G.; FERREIRA, G. M.; BARBÉRIO, A. Cytotoxic and genotoxic assessment of surface water from São Paulo State, Brazil, during the rainy and dry seasons. Ecotoxicology, v. 25, p. 633-645, 2016. http://dx.doi.org/10.1007/s10646-016-1622-1

SÃO PAULO (Estado). Secretaria de Estado de Economia e Planejamento. Plano regional do macroeixo paulista. São Paulo, 1978.

SILVA, F. C.; FORTES NETO, P.; FORTES, N. L. P.; BALLESTERO, S. D. Quantification of the release of $\mathrm{CO} 2-\mathrm{C}$ and $\mathrm{C} / \mathrm{N}$ ratio during composting of urban waste. HOLOS Environment, v. 13, n. 1, p. 9-23, 2013 a.

SILVA, L. C.; ALMEIDA, J. C. R. de; SILVA ALMEIDA, A. A . Ocorrência de chumbo e zinco nos solos e plantas às margens de uma rodovia de tráfego veicular intenso. Revista Ambiente \& Água, v. 8, p. 50-59, 2013b. http://dx.doi.org/10.4136/ambiagua. 1256

TARGA, M. dos S.; ALMEIDA, A. A. da S. Fifteen years of the graduate program of Environmental Sciences of the University of Taubaté. Revista Ambiente \& Agua, v. 8, n. 4, p. 4-7, 2014. http://dx.doi.org/10.4136/ambi-agua.1451

TARGA, M. dos S.; BATISTA, G. T. Benefits and legacy of the water crisis in Brazil.

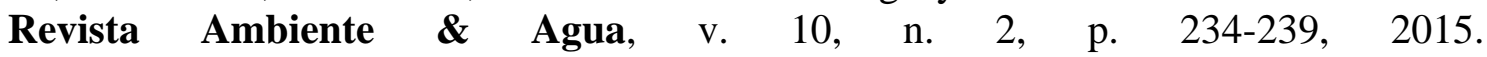
http://dx.doi.org/10.4136/ambi-agua.1629

VIEIRA, E. T. Industrialização e desenvolvimento: uma análise das políticas públicas regionais no Vale do Paraíba paulista a partir da década de 1970. In: CONGRESSO INTERNACIONAL DE HISTÓRIA, 4., 2009. Anais eletrônicos... Brasília: PPH/UEM, 2009. http://dx.doi.org/10.4025/4cih.pphuem.238

VILARON, M. A.; FISCH, G. Caracterização do início do período chuvoso no Vale do Paraíba paulista. Revista Ambiente \& Água, v. 8, p. 36-49, 2014. http://dx.doi.org/10.4136/ambi-agua.1254 